\title{
Phytochemical Screening and In-vitro Antibacterial Activity of Mangifera indica (Mango) Kernel on Aeromonas caviae
}

\author{
A. M. Talba ${ }^{1 *}$, M. M. Suleiman ${ }^{2}$, M. A. Raji ${ }^{3}$, S, J. Oniye ${ }^{4}$ \\ ${ }^{1}$ Veterinary Teaching Hospital, Ahmadu Bello University, Zaria-Nigeria \\ ${ }^{2}$ Department of Veterinary Pharmacology and Toxicology, Faculty of Veterinary Medicine, Ahmadu Bello \\ University, Zaria-Nigeria \\ ${ }^{3}$ Department of Veterinary Microbiology, Faculty of Veterinary Medicine, Ahmadu Bello University, Zaria- \\ Nigeria \\ ${ }^{4}$ Department of Biological Science, Faculty of Science, Ahmadu Bello University, Zaria-Nigeria
}

\begin{abstract}
OBJECTIVE: To determine the phytoconstituents of Mangifera indica kernel and its antibacterial activity against Aeromonas caviae.

METHODS: Methanol extract of mango kernel was used to identify secondary metabolites of mango kernel. Aqueous and methanol extracts of mango kernel were tested in-vitro for antibacterial activity. Colony of pure culture of A. caviae was inoculated onto sterile plate of Muller-Hinton agar. Five wells (6mm in diameter) were made in circular pattern equidistance in each of the plates using a sterile cup borer. One hundred microliters of different concentrations of both aqueous and methanol extracts of mango kernel were placed into the wells using sterile pipettes and 100 $\mathrm{l}$ of sterile distilled water in a given well as negative control. The test was performed in triplicates ( 3 plates for every extract), the plates were incubated at $37^{\circ} \mathrm{C}$ for 24 hours.
\end{abstract}

RESULTS: Phytochemical screening revealed the presence of Carbohydrates, Triterpenes, Unsaturated sterols, Cardiac glycosides, Saponins, Tannins and Flavonoids. Methanol extract used at different concentrations showed varying degrees of inhibition against A. caviae (ranging from $16 \pm 2.41 \mathrm{~mm}$ to $24 \pm 0.58$ $\mathrm{mm}$ ) except that the aqueous extract was found to be slightly active against the organism at lower concentrations with zones of inhibition ranging from $8 \pm 1.22 \mathrm{~mm}$ to $11 \pm 1.23 \mathrm{~mm}$ with measurable zones of inhibition at higher concentrations.

CONCLUSION: Methanol extract of mango kernel at different concentrations inhibited the growth of A. caviae.

KEYWORDS: Phytochemical analysis, M. indica kernel, In-vitro, A. caviae, Antibacterial activity.

\section{INTRODUCTION}

Herbal medicines are also known to exhibit anti-microbial activities, facilitate growth, and maturation of cultured fish species. Besides, under intensive farming, the anti-stress characteristics of herbs will be of immense benefit without posing risk of environmental hazard [1] Mangifera indica L., which belongs to the Anacardiaceae family, is a large evergreen tree of tropical and subtropical regions of the world. M. indica grows in the tropical and subtropical region and its parts are commonly used in folk medicine for a wide variety of remedies [2]. Different parts of mango have a broad range of medicinal properties, such as antimicrobial [3], antiviral, antifungal [4], anti-inflammatory [5], anti-diarrhoeal [6], antioxidant [7], as well as immunomodulatory [8]. Of all the by-products of mango tree, its kernel is the cheapest and most readily available. Huge amounts of unutilized mango kernels, can be used as feed additives to enhance non-specific immunity in fish [9].

Aeromonas caviae is a ubiquitous bacteria in aquatic environments [10]. The agent is known to cause several fish diseases including; Motile Aeromonas Septicemia (MAS) in carp, tilapia, catfish, and salmon, red sore disease in bass and carp, and ulcerative infections in catfish, cod, carp, and goby [11]. The disease has several presentations. This ranges from a subacute with no clinical signs, an acute form characterized by septicemia with accompanying hemorrhages at the bases of fins, inappetence and melanosis and finally the chronic form in older fish consisting of exophthalmia and hemorrhaging in muscles and internal organs [12]. 
A number of approaches were employed to control diseases in fish including sanitary prophylaxis, disinfection, and chemotherapy with particular emphasis on the use of antibiotics [13]. However, application of antibiotics and chemicals in aquaculture is often expensive and undesirable since indiscriminate use could lead to antibiotic resistance and consumer reluctance to buy fish with antibiotics residues. However, there is little information on the use of plant extracts in limiting the effect of A. caviae infection in fish farming in Nigeria. The study is aimed at determining the effect of both aqueous and methanol extracts of mango kernel on $A$. caviae.

\section{MATERIALS AND METHODS}

Identification of mango specie used in the study : The mango species used in this study were identified by their leaves at Herbarium Department of Biological Sciences, A.B.U. Zaria, and a voucher specimen no. 1944 was then assigned.

Collection of the mango seeds, removal and processing of the kernel : Mangifera indica seeds were collected from mango trees around Ahmadu Bello University (ABU) Samaru, Zaria. The seeds were washed repeatedly under running tap water crushed and the kernels were removed. The kernels were air-dried at room temperature and then made into powder using mortar and pestle. The powder was preserved in an airtight polythene bag and kept in a cool dry place until used.

Preparation of the aqueous extract of mango kernel : Concentrations of 50, 55.6, 100, 125, 166, 250 and 500 $\mathrm{mg} / \mathrm{ml}$ of the powdered mango kernel were prepared using sterile distilled water. Twenty milliliters of distilled water was added to $1 \mathrm{~g}$ of the grounded kernel to achieved $50 \mathrm{mg} / \mathrm{ml}$ concentration. In a similar manner, $1 \mathrm{~g}$ in $18 \mathrm{ml}, 1 \mathrm{~g}$ in $12 \mathrm{ml}, 1 \mathrm{~g}$ in $10 \mathrm{ml}, 1 \mathrm{~g}$ in $8 \mathrm{ml}, 1 \mathrm{~g}$ in $6 \mathrm{ml}, 1 \mathrm{~g}$ in $4 \mathrm{ml}$ and $1 \mathrm{~g}$ in $2 \mathrm{ml}$ for $55.6,100,125,166,250,500$ $\mathrm{mg} / \mathrm{ml}$ concentrations respectively. The different concentrations of the extract were refrigerated at $4{ }^{\circ} \mathrm{C}$ until used.

Preparation of methanol extract of mango kernel : The component of $200 \mathrm{~g}$ of the powdered kernel was extracted exhaustively over a period of 24 hours using continuous extraction method with $350 \mathrm{ml}$ of methanol in a soxhlet extractor [14] The extract was concentrated to a solid form using water bath at $60^{\circ} \mathrm{C}$ for 24 hours. Twenty milliliters of distilled water was added to $1 \mathrm{~g}$ of the grounded kernel to achieved $50 \mathrm{mg} / \mathrm{ml}$ concentration. In a similar manner, $1 \mathrm{~g}$ in $18 \mathrm{ml}, 1 \mathrm{~g}$ in $12 \mathrm{ml}, 1 \mathrm{~g}$ in $10 \mathrm{ml}, 1 \mathrm{~g}$ in $8 \mathrm{ml}, 1 \mathrm{~g}$ in $6 \mathrm{ml}, 1 \mathrm{~g}$ in $4 \mathrm{ml}$ and $1 \mathrm{~g}$ in $2 \mathrm{ml}$ for 55.6 , $100,125,166,250,500 \mathrm{mg} / \mathrm{ml}$ concentrations respectively. The different concentrations of the methanol extract of mango kernel were refrigerated at $4^{\circ} \mathrm{C}$ until used.

Phytochemical screening : Phytochemical screening of the methanol extract of mango kernel was carried out using standard phytochemical methods [15] to identify its constituents.

Microorganism used : Aeromonas caviae isolates were obtained from Department of Veterinary Microbiology, Ahmadu Bello University, Zaria Nigeria.

Antimicrobial activity test : Agar well diffusion method [16] (with slight modification) was used to test for antimicrobial activity of the methanol and aqueous extracts of mango kernel. Overnight culture of A. caviae grown on Mueller-Hinton agar plates was used. Colony of cultured bacteria was inoculated onto sterile Mueller-Hinton agar plates. Five equidistant wells $(6 \mathrm{~mm}$ in diameter) were made in each of the 6 plates using a sterile cup borer. One hundred microlitres of different concentrations of both aqueous and methanol extracts of mango kernel were put individually into the wells using sterile pipettes and $100 \mu \mathrm{l}$ of sterile distilled water in a given well and they were allowed to diffuse at room temperature for 2 hours. Thereafter, the plates were incubated at $37^{\circ} \mathrm{C}$ for 24 hours.

Antibiotic sensitivity test : The Agar Disc Diffusion (Kirby-Bauer method) which conforms to the recommendation of NCCLS (National Committee for Clinical Laboratory Standards) was used to evaluate the activity of standard antibiotics [17]. Six different antibiotics disc namely: Gentamycin (G) $10 \mu \mathrm{g}$, Enrofloxacin (EN) $5 \mu \mathrm{g}$, Erythromycin (E) $5 \mu \mathrm{g}$, Neomycin (N) $10 \mu \mathrm{g}$, Chloramphenicol (C) $30 \mu \mathrm{g}$ and Tetracycline (T) 30 $\mu \mathrm{g}$ were used in triplicate for the sensitivity test. The antibiotic discs were aseptically placed over the MuellerHinton agar plates seeded with A. caviae, the test was repeated in triplicates .The discs were sufficiently separated from each other to avoid overlapping of inhibition zones. The plates were incubated at $37^{\circ} \mathrm{C}$ for 24 hours, diameter of the inhibition zones was measured in $\mathrm{mm}$. All the media used in the present study were obtained from Hi-media Laboratories Ltd., Mumbai, India. 


\section{RESULTS}

Phytoconstituents of $\boldsymbol{M}$. indica kernel : Phytochemical screening test revealed the presence of carbohydrates, triterpenes, unsaturated sterols, cardiac glycosides, saponin, tannins and Flavonoids (Table 1).

Antibacterial activity test of aqueous and methanol $M$. indica kernel extract : The aqueous extract of $M$. indica kernel was found to be slightly effective against the test organism at lower concentrations $(166,125,100$, 55.6 and $50 \mathrm{mg} / \mathrm{ml}$ ) with smaller zones of inhibition that ranges from $8 \pm 1.22 \mathrm{~mm}$ to $11 \pm 1.23 \mathrm{~mm}$, There were no measurable zones of inhibition at higher concentrations of the aqueous extract that is 250 and 500 $\mathrm{mg} / \mathrm{ml}$ (Table 3). While the methanol extract of $M$. indica kernel used at different concentrations showed varying degrees of inhibition against the bacterial specie (A. caviae) with inhibition zones ranging from $16 \pm 2.41$ $\mathrm{mm}$ to $24 \pm 0.58 \mathrm{~mm}$ (Table 2) with no inhibition around the well seeded with distilled water (Plate 1).

\section{Antibiotic sensitivity test}

Six standard antibiotics used in the test showed variable degrees of inhibition that ranges from $14 \pm 0.22 \mathrm{~mm}$ to $20 \pm 0.32 \mathrm{~mm}$ (Table 4). Although, tetracycline did not show measurable inhibition zones against the test organism (Plate 2).

\section{DISCUSSION}

The aqueous extract of $M$. indica kernel did show slight antibacterial activity against $A$. caviae at lower concentration, with no activity at higher concentrations. This might be as a result of inability of the aqueous extract to diffuse into the media at higher concentrations, due to the thickness of the extract of $M$. indica kernel at higher concentration of 250 and $500 \mathrm{mg} / \mathrm{ml}$. However, the aqueous extract (at lower concentration) temporarily inhibited growth of the test organism over short period of time. This is because the bacterial growth was restored eight hours post incubation, which could be due to limited effect of the aqueous extract on the test organism. The antibacterial properties exhibited by 2 different extracts of $M$. indica kernel in this study, could be attributed to the presence of steroidal saponins, flavonoids, tannins and other polyphenolic compounds. This is in line with the findings of Manjunatha and Tereschuk $[19,20]$ who reported antibacterial activities of tannins and flavonoids isolated from mango kernel. The antibacterial effect of the different phytoconstituents of M. indica kernel may perhaps present a synergistic action against the tested organism.

This study also confirms the use of organic polar solvent (methanol) in the preparation of mango kernel extract to yield better results as compared to aqueous extracts. In this study, organic solvent (methanol) did not negatively affect the bioactivity of mango kernel against $A$. caviae, but rather provided the best antimicrobial effect. This might be because of some additional antimicrobial components that were extracted by organic polar solvent [21]. The finding is in concordance with a previous report by Khammuang and Sarnthima [22], where different mango kernel extracts showed interesting antibacterial activity against both Gram positive and Gram negative bacteria as determine by disc diffusion method. The standard antibiotics used, showed considerable inhibition zones against the tested organism with no measurable inhibition zone around the tetracycline disc, which indicated possible resistance of the organism to tetracycline. This could possibly be due to the indiscriminate use of tetracycline in aquaculture and the resultant resistance of fish pathogens to the therapeutic agent (tetracycline), as tetracycline appears to be the commonest antibiotic utilized for aquatic treatment. In conclusion, both aqueous and methanol extracts of mango kernel possesses antibacterial activity. However, the antibacterial activity exhibited by aqueous extract of mango kernel against the test organism was lower compared to that of the methanol extract. The antibacterial activity of the $M$. indica kernel could be due to the presence of one or more of the secondary metabolites detected such as flavonoids, tannins, triterpenes and saponins which were earlier shown to have antibacterial effect if properly harnessed.

Conflict of interest statement : The authors hereby declare that there is no conflict of interest.

\section{Acknowledgement}

The authors are grateful to the Department of Veterinary Microbiology, Ahmadu Bello University, Zaria, Nigeria, for providing a bench space and the isolate of A. caviae used in the experiment.

\section{REFERENCE}

[1] Harikrishnan, R., Rani, M., Balasundaram, C. Hematological and Biochemical Parameters in Common Carp,Cyprinus Carpio, Following Herbal Treatment for A. hydrophila infection, Aquaculture, 2003; 31:409-412.

[2] Coe, F.G., Anderson, G.J. Screening of medicinal plants used by the Gar'ifuna of eastern icaragua for bioactive compounds. J. Ethnopharm. 1996; 53:29-50. 
[3] Keita, Y., Kone, O., Ly, A. K. and Hakkinen, V. Chemical and antibacterial activity of some Guinean mango varieties distillates. Comptes Rendus CXhimie 2004; 7(10-11):1095-1100.

[4] Cojocaru, M., Droby, S., Glotter, E., Goldman, A., Gottlieb, H.E., Jacoby, B. 5-(12-heptadecenyl)-resorcinol, the major component of the antifugal activity in the peel of mango fruit. Phyto., 1986; 25:1093-5.

[5] Garrido, G., Gonzalez, D., Lemus, Y., Garcia, D., Lodeiro, L., Quintero, G. (2004). In- vivo and in vitro anti-inflammatory activity of Mangifera indica L. extract (VIMANG). Pharm. Res. 1986; 50:143-149.

[6] Sairam, K., Hemalata, S., Kumar, A., Srinivasan, T., Ganesh, J., Shankar, M. Evaluation of anti-diarrhoeal activity in seed extracts of Mangifera indica. J. Enthnopharm. 2003; 84:11-15.

[7] Scartezzini, P., Speroni, E., Review on some plants of Indian traditional medicine with antioxidant activity. J. Ethnopharm. 2002; 71:23-4.

[8] Makare, N., Bodhankar, S., Rangari, V., Immunomodulatory activity of alcoholic extract of Mangifera indica L. in mice. J. Ethnopharm., 2001; 78:133-137.

[9] Sahu, S., Das, B. K., Pradhan, J., Mohapatra, B. C., Mishra, B. K., Sarangi, N. Effect of Magnifera indica kernel as a feed additive on immunity and resistance to Aeromonas hydrophila in Labeo rohita fingerlings. Fish \& shellfish immune. 2007; 23: 109-118

[10] Janda, J. M., Abbott, S. L. The Genus Aeromonas: Taxonomy, Pathogenecity and Infection. Clin. Microb. Rev. 2010; 23(1): 35-73.

[11] Joseph, S. W., Carnahan. A. The isolation, identification, and systematics of the motile Aeromonas species. Annual Rev. of Fish Dis. 1994; 4:315-343.

[12] Austin, B., Adams, C. Fish pathogens, In B. Austin, M. Altwegg, P. J. Gosling, and S. Joseph (ed.), The genus Aeromonas. John Wiley \& Sons Ltd., West Sussex, England. 1996; pp. 197-243.

[13] Harikrishnan, R., Balasundaram, C., Heo, M. Review: Impact of Plant Products on innate and Adaptive Immune system of cultured finfish and shellfish. Aquaculture 2011;317: 1-15.

[14] Harborne, J.B. Phytochemical methods: A guide to modern techniques in plants analysis. 2nd Edition, chapman and Hall, London; 1984; Pp. 1-10, 100-117.

[15] Evans, W.C. Trease and Evans Pharmacognosy $16^{\text {th }}$ edition, Baillienne Tyndall London, UK.. 2009.

[16] Perez, C., Paul, M., Bazerque, P. Antibiotic assay by agar-well diffusion method. Acta. Biology and Medical Experience, 1990; 15: 113-115.

[17] Bauer, A.W., Kirby, M.M., Sherris, J.C., Truck, M. Antibiotic susceptibility testing by a standardized single disk method. Amer.J Clin. Path., 1966; 45: 493-6.

[18] Yakubu, M.T., Akanji, M.A., Oladiji, A.T. Aphrodisiac potentials of the aqueous extract of Fadogia agrestis (Schweinf. Ex Hiern) stem in male albino rats Asian Journal of Andrology 2005; 7(4): 399-404.

[19] Manjunatha, B.K. Antibacterial activity of Pterocarpus santalinus. Indian Journal of Pharmaceutical Science, 2006; 68(1): 115116.

[20] Tereschuk, M.L., Riera, M.V., Castro, G.R., Abdala, L.R. Antimicrobial activity of flavonoids from leaves of Tagetes minuta. J. Ethnopharm.. 1997; 1(56):227-32.

[22] Khammuang, S. and Sarnthima, R. Antioxidant and Antibacterial activities of selected varieties of Thai mango seed extract. Pakistani Journal of Pharmaceutical Sciences, 1997; 24(1): 37-42.

\section{APPENDIXES}

Table 1: Phytochemical Constituents of Mango kernel.

\begin{tabular}{lc}
\hline Phytochemicals & inference \\
\hline Carbohydrates & + \\
Anthraquinones & - \\
Triterpenes & + \\
Unsaturated sterols & + \\
Cardiac glycosides & + \\
Saponin & + \\
Tannins & + \\
Flavonoids & + \\
Alkaloids & - \\
\hline
\end{tabular}

$+=$ Present

- = Absent

Table 2: Mean \pm SD in vitro antimicrobial activity of methanol extracts of $M$. indica kernel on A. caviae using modified agar well diffusion method.

\begin{tabular}{lc}
\hline Concentration $(\mathrm{mg} / \mathrm{ml})$ & Diameter of inhibition zones $(\mathrm{mm})$ \\
\hline 50 & $16 \pm 2.41$ \\
55.6 & $17 \pm 2.19$ \\
100 & $18 \pm 1.53$ \\
125 & $20 \pm 0.33$ \\
166 & $20 \pm 0.33$ \\
250 & $23 \pm 0.33$ \\
500 & $24 \pm 0.58$ \\
\hline
\end{tabular}

Table 3: Mean \pm SD in vitro antimicrobial activity of aqueous extract on $A$. caviae using modified agar well diffusion method.

\begin{tabular}{lc}
\hline Concentration $(\mathrm{mg} / \mathrm{ml})$ & Diameter of inhibition zones $(\mathrm{mm})$ \\
\hline 50 & $8 \pm 1.22$ \\
55.6 & $9 \pm 0.50$ \\
\hline
\end{tabular}


Phytochemical Screening And Invitro Antibacterial...

\begin{tabular}{ll}
\hline 100 & $9 \pm 1.50$ \\
125 & $8 \pm 0.50$ \\
166 & $11 \pm 1.23$ \\
250 & NI \\
500 & NI \\
\hline
\end{tabular}

$\mathrm{NI}=$ No observable inhibition (Note: Original well size is $6 \mathrm{~mm}$ diameter)

Table 4: Mean \pm SD in vitro antibacterial activity of six (6) different antibiotics on A. caviae using agar disc diffusion method.

\begin{tabular}{llc}
\hline Standard Antibiotics & Conc. $(\mathrm{mg})$ & Diameter of inhibition in $\mathrm{mm}$ \\
\hline Chloramphenicol $(30 \mu \mathrm{g})$ & 0.03 & $14 \pm 0.22$ \\
Enrofloxacin $(5 \mu \mathrm{g})$ & 0.005 & $18 \pm 0.21$ \\
Erythromycin $(5 \mu \mathrm{g})$ & 0.005 & $17 \pm 0.33$ \\
Gentamycin $(10 \mu \mathrm{g})$ & 0.01 & $20 \pm 0.32$ \\
Neomycin $(10 \mu \mathrm{g})$ & 0.01 & $15 \pm 0.22$ \\
Tetracycline $(30 \mu \mathrm{g})$ & 0.03 & - \\
\hline
\end{tabular}

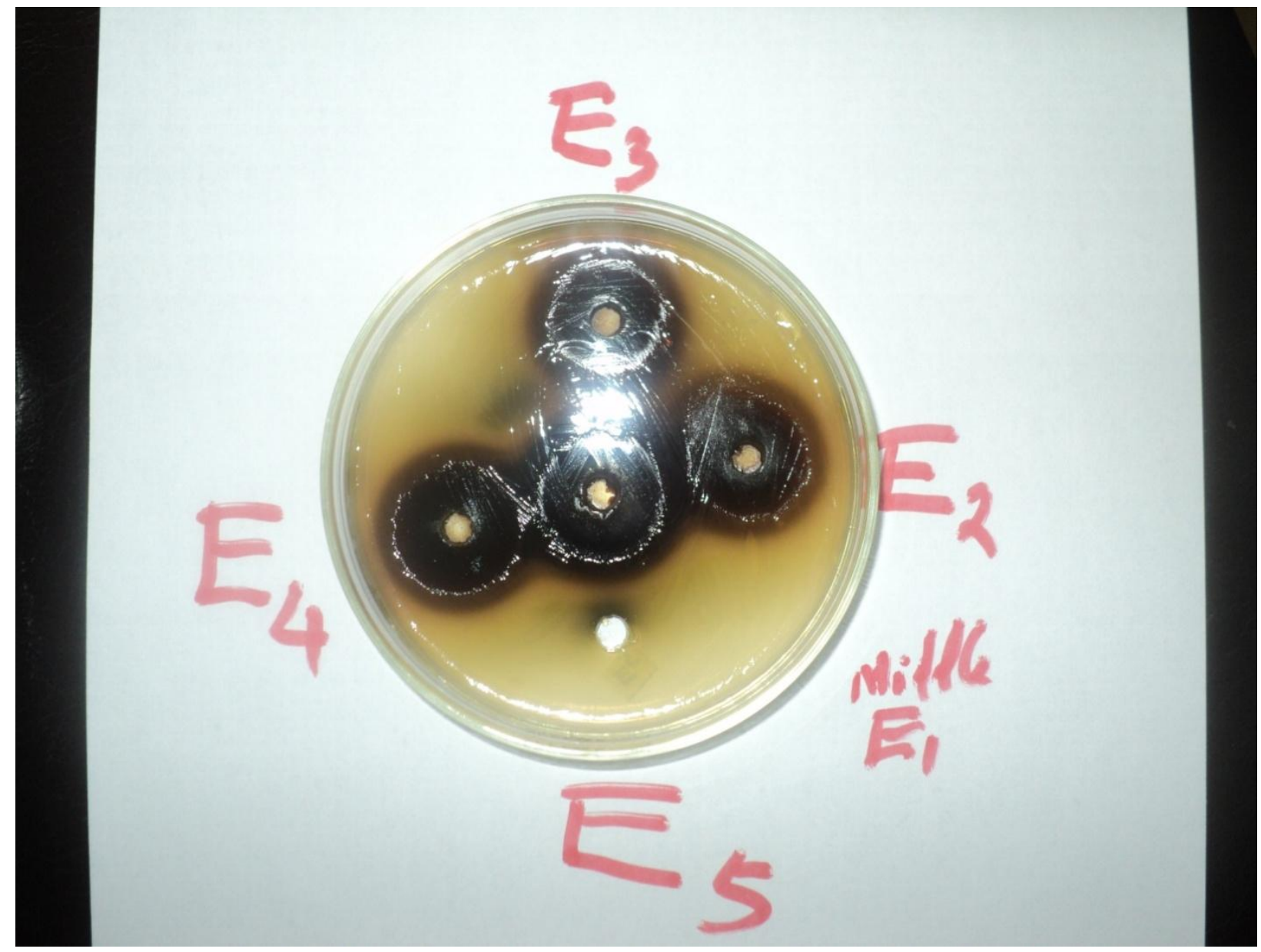

Plate 1: Zones of inhibition at four (4) different concentrations (125, 166, 250 and $500 \mathrm{mg} / \mathrm{ml}$ ) of the methanolic extract of $M$. indica kernel, $\mathrm{E}_{1}-\mathrm{E}_{4}$ respectively with well $\mathrm{E}_{5}(100 \mu \mathrm{l}$ of distilled water $)$ showing no inhibition. 


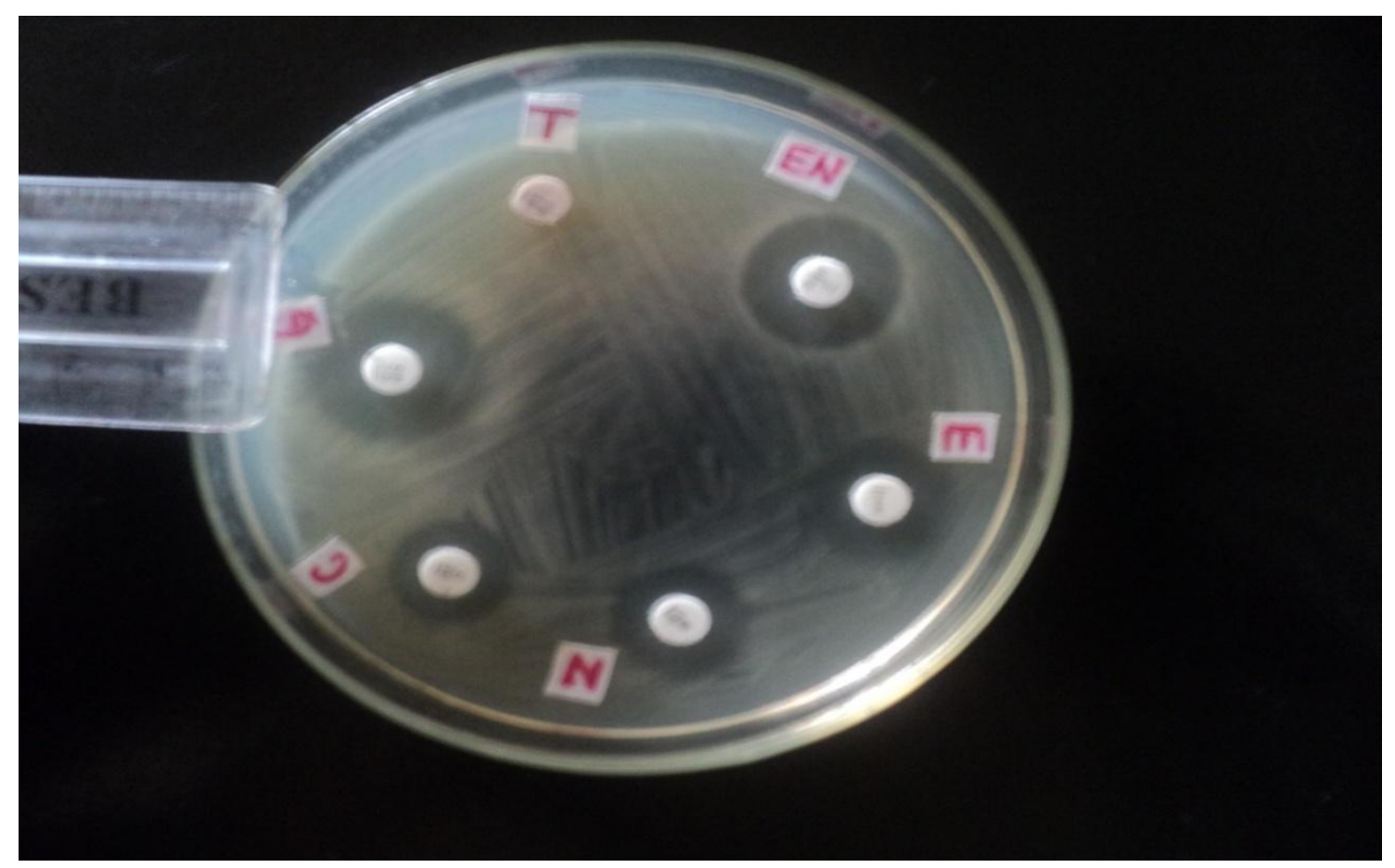

Plate 2: Different antibiotics at different concentrations showing variable degree of inhibition, Gentamicin 10 $\mu \mathrm{g}(\mathrm{G})$, Enrofloxacin $5 \mu \mathrm{g}(\mathrm{EN})$, Erythromycin $5 \mu \mathrm{g}$ (E), Neomycin $10 \mu \mathrm{g}(\mathrm{N})$, Chloramphenicol $30 \mu \mathrm{g}(\mathrm{C})$ and Tetracycline $30 \mu \mathrm{g}(\mathrm{T})$ [Agar disc diffusion method]. 